\title{
Removal of Paramagnetic lons Prior to Analysis of Organic Reactions in Aqueous Solutions by NMR Spectroscopy
}

\author{
Rio Febrian, ${ }^{\dagger}$ Joseph P. Roddy, ${ }^{\dagger}+$ Christine H. Chang, ${ }^{\dagger}$ Clinton T. Devall, $^{\dagger}$ and Paul J. Bracher* ${ }^{*}{ }^{\dagger}$ \\ ${ }^{\dagger}$ Department of Chemistry, Saint Louis University, 3501 Laclede Avenue, St. Louis, Missouri 63103, United States \\ ${ }^{\ddagger}$ Division of Chemistry \& Chemical Engineering, California Institute of Technology, 1200 E. California Blvd., Pasadena, California \\ 91125, United States
}

Supporting Information

ABSTRACT: This article describes a method for improving ${ }^{1} \mathrm{H}$ NMR spectra of aqueous samples containing paramagnetic metals by precipitation of metal cations with a variety of counteranions. The addition of hydroxide, phosphate, carbonate, and arsenate to solutions of transition metals such as $\mathrm{Fe}^{2+}$ and $\mathrm{Mn}^{2+}$ can reduce line broadening and improve the ability of a spectrometer to lock on the signal of deuterium. The method is most effective under strongly alkaline conditions, and care must be taken to observe whether the organic substrates undergo side reactions or are themselves removed from solution upon addition of the precipitating salts. As a demonstration of the practical value of the method, we show that NMR spectroscopy can be used to monitor the transition-metal-mediated hydrolysis of glycylglycine $\left(\mathrm{Gly}_{2}\right)$.

\section{INTRODUCTION}

NMR spectroscopy is one of the most powerful methods for the characterization of organic compounds and study of organic reactions. Paramagnetic species can render NMR spectroscopy impracticable by broadening spectral peaks and hindering the ability of spectrometers to lock on the signal of deuterium. In this article, we explore the precipitation of paramagnetic cations with a variety of counteranions as a means to improve ${ }^{1} \mathrm{H}$ NMR spectra sufficiently to measure rates of organic reactions in water. We show that-in certain circumstances-the removal of paramagnetic ions by these methods can decrease line broadening in spectra without initiating side reactions or affecting the concentration of the organic solutes present. We demonstrate this method by using it to measure the hydrolysis of a peptide in concentrated (1 M) solutions of various transition metals, for which direct analysis by NMR spectroscopy would otherwise be impossible. We discuss several significant limitations to the method, particularly its requirement for strongly alkaline conditions and the potential for the solid phase to adsorb organic molecules from the mother liquor.

Background. We are interested in studying the kinetics of reactions of biologically relevant organic compounds in water to evaluate theories that propose roles for these molecules in the origin of life. ${ }^{1,2}$ In a previous study, we measured rate constants for the hydrolysis of thioesters using ${ }^{1} \mathrm{H}$ NMR spectroscopy to monitor the change in concentration of reactants over time. ${ }^{3}$ The samples in this study were relatively simple solutions in water with a buffer salt (to maintain a constant $\mathrm{pH}$ and enable pseudo-first-order kinetics) and an internal standard (to measure accurate concentrations of the thioester). Other studies have shown that transition metal ions can affect the reactivity of peptides and thioesters. ${ }^{4-12}$ Given that the prebiotic ocean was unlikely to have resembled as clean a system as water with a mild $\mathrm{pH}$ buffer, ${ }^{7,13}$ we wished to explore the effect of various dissolved metals on reactions of prospective prebiotic relevance.

The universal dependence of modern biology on water suggests that life originated in an aqueous environment. Scientists disagree over the composition of the prebiotic ocean, but it is widely assumed that several aqueous metal ions were present. In addition to diamagnetic metals such as $\mathrm{Na}^{+}, \mathrm{K}^{+}$, $\mathrm{Mg}^{2+}$, and $\mathrm{Ca}^{2+}$, paramagnetic metals such as $\mathrm{Fe}^{2+}, \mathrm{Mn}^{2+}$, and $\mathrm{Co}^{2+}$ are also conjectured to have been present in Earth's ancient ocean. ${ }^{13,14}$ Many theories and experiments regarding prebiotic chemistry invoke conditions where reaction mixtures are subjected to wet-dry cycles of hydration (e.g., by rain) and evaporation. ${ }^{15-20}$ The process of evaporation of a trapped body of water introduces the potential for significantly higher concentrations of metal ions than in the prebiotic ocean itself-presumably approaching their limit of solubility with whatever counteranions are present in the system.

Paramagnetic ions can present a considerable challenge to analysis by NMR spectroscopy. The broadening of peaks in samples containing paramagnetic species has been studied extensively. ${ }^{21,22}$ As the magnetic susceptibility $(\chi)$ of an aqua

Received: August 13, 2019

Accepted: October 14, 2019

Published: May 28, 2021 
ion increases, the broadening of peaks in the NMR spectrum of a sample also increases. This broadening can complicate spectra by causing peaks to overlap that would otherwise resolve cleanly. Figure 1 documents how increasing the

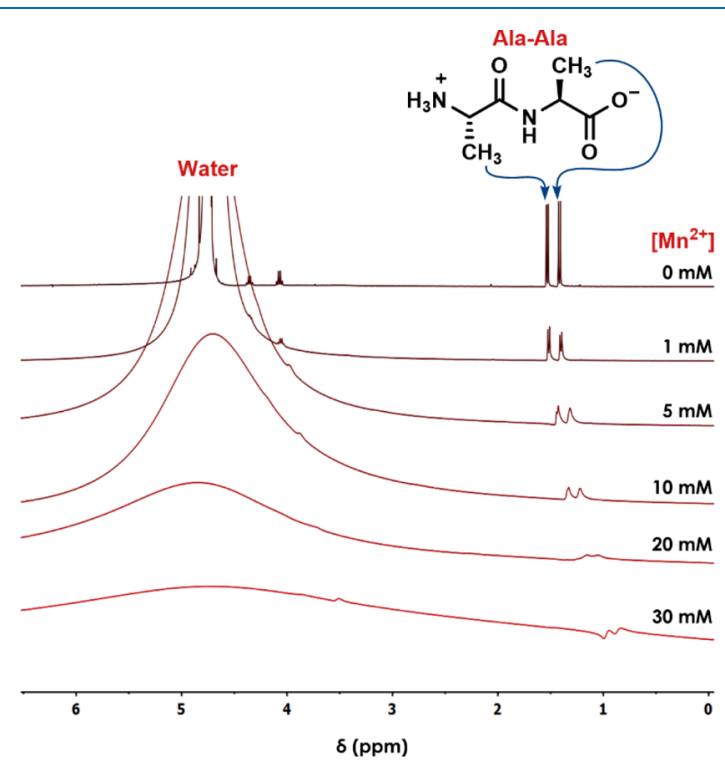

Figure 1. Challenges in monitoring reactions by ${ }^{1} \mathrm{H}$ NMR spectroscopy with paramagnetic ions present. ${ }^{1} \mathrm{H}$ NMR spectra of $\mathrm{L}$ alanyl-L-alanine $\left(\mathrm{Ala}_{2}\right)$ in $1: 1 \mathrm{D}_{2} \mathrm{O} / \mathrm{H}_{2} \mathrm{O}$ with varying concentrations of $\mathrm{MnCl}_{2}$. The increasing concentration of paramagnetic $\mathrm{Mn}^{2+}$ progressively broadens the signals of each spectrum. As $\left[\mathrm{Mn}^{2+}\right]$ increases, the methine quartets are quickly subsumed by the broadened water peak, whereas the structure of the methyl doublets is lost.

concentration of $\mathrm{Mn}^{2+}$ from 0 to $10 \mathrm{mM}$ broadens the signals in ${ }^{1} \mathrm{H}$ NMR spectra of the simple peptide $\mathrm{Ala}_{2}$, whereas further increases in concentration make the spectra unintelligible. Millimolar concentrations of paramagnetic ions often make it difficult for spectrometers to attain a stable lock because of the broadening of the deuterium signal. The broadened signal for water can overrun signals of the analyte. ${ }^{23}$ To monitor the kinetics of reactions in the presence of large concentrations of paramagnetic species, a method to remove or quench these species prior to analysis is necessary.

Strategies to remove paramagnetic species or reduce their influence during analysis by NMR spectroscopy have been described in the literature. ${ }^{24-26}$ The general methods most commonly reported are chelation and precipitation. Ding and co-workers improved ${ }^{31} \mathrm{P}$ NMR spectra of environmental samples that contained paramagnetic metal ions, including $\mathrm{Fe}^{3+}$ and $\mathrm{Mn}^{2+}$, by 8 -hydroquinoline-assisted precipitation. ${ }^{27}$ In another approach, Barge et al. removed $\mathrm{Fe}^{2+}$ and $\mathrm{Fe}^{3+}$ by precipitation with hydroxide prior to analysis by ${ }^{1} \mathrm{H}$ NMR spectroscopy. ${ }^{28}$ Other approaches have attempted to improve NMR spectra of paramagnetic samples by altering the parameters of the acquisition experiment. Although helpful for qualitative measurements, these methods are sometimes less effective for experiments that require quantitative accuracy, such as kinetics measurements. ${ }^{29,30}$

\section{RESULTS AND DISCUSSION}

In developing a method for the analysis of organic reactions in water containing paramagnetic transition metals, it was clear that any method used to prepare samples for analysis by NMR spectroscopy should: (i) be simple, (ii) be rapid, (iii) be inexpensive, (iv) remove enough of the paramagnetic metal to enable the instrument to lock on the signal of deuterium, (v) remove enough of the metal such that at least one peak in the spectrum of the substrate was resolved from the rest of the spectrum of the reaction mixture, and (vi) not affect the concentration of the organic substrate present in the sample.

In searching for a more straightforward alternative to adding new reagents to our samples, we first attempted to precipitate the paramagnetic species present by the addition of a less polar solvent that was miscible with water (e.g., dimethylsulfoxide or tetrahydrofuran). We found that adding quantities as high as 3:1 (v/v, organic solvent/water) did not remove enough metal to be effective. Methods such as liquid-liquid extraction into an organic phase or evaporation of the solvent followed by solid-liquid extraction into a deuterated organic solvent seemed too impractical to attempt.

Inspired by previous reports, ${ }^{27,28}$ we pursued the idea of precipitating insoluble salts of the paramagnetic metals as a means of preparing aliquots of reaction mixtures for subsequent analysis by NMR spectroscopy. Our primary goal was to find alternatives to the use of hydroxide, as we knew that many substrates of presumed prebiotic importancesimilar to thioesters-hydrolyze rapidly in strongly alkaline conditions. For instance, thioesters are not stable at high $\mathrm{pH}$. $S$-Methylthioacetate, the simplest example of an alkyl thioester, has a half-life of $43 \mathrm{~s}$ at $\mathrm{pH} 13$ and a half-life of $7.2 \mathrm{~min}$ at $\mathrm{pH}$ $12 .^{3}$ A quick survey of the solubility product constants $\left(K_{\mathrm{sp}}\right)$ for a variety of inorganic salts of our target metals suggested that carbonate $\left(\mathrm{CO}_{3}{ }^{2-}\right)$, phosphate $\left(\mathrm{PO}_{4}{ }^{3-}\right)$, and arsenate $\left(\mathrm{AsO}_{4}{ }^{3-}\right.$ ) could be particularly effective (see Table $\mathrm{S} 1$ in the Supporting Information). Seeking to extend our previous work, ${ }^{1}$ we selected the transition-metal-mediated hydrolysis of peptides and thioesters as model reactions to monitor by the method.

Figure 2 depicts the basic procedure for the precipitation method. A stock solution of the precipitating agent was dispensed into an aliquot of a reaction mixture, and the resulting solid was isolated by centrifugation. The supernate was mixed with an equal volume of deuterated water $\left(\mathrm{D}_{2} \mathrm{O}\right)$ for analysis by NMR spectroscopy. In general, the method was able to remove enough paramagnetic metal (e.g., $\mathrm{Fe}^{2+}$ or $\mathrm{Mn}^{2+}$ ) from the solutions to permit the NMR spectrometer to lock on the signal of deuterium. The analysis of a sample of 25 $\mathrm{mM} \mathrm{Gly} y_{2}$ and $20 \mathrm{mM} \mathrm{MnCl}_{2}$ was enabled by the addition of a variety of salts, including $\mathrm{K}_{3} \mathrm{PO}_{4}, \mathrm{~K}_{2} \mathrm{CO}_{3}, \mathrm{Na}_{3} \mathrm{HAsO}_{4}$, and $\mathrm{KOH}$ (Figure 3). For the spectra without water suppression, the broadening of the peak for water extended into the signals for the $\mathrm{Gly}_{2}$ substrate when $20 \mathrm{mM} \mathrm{MnCl}$ was in solution. Addition of the salts reduced the broadening of the water peak such that integration of the signals for $\mathrm{Gly}_{2}$ was reliable. Importantly, the removal of $\mathrm{Mn}^{2+}$ from the solutions improved the spectral resolution without changing the concentration of the peptide analyte, which was verified from both the ratios of the peak integrations for $t$-butanol (singlet, $\delta=0.95 \mathrm{ppm}$ ) as an internal standard against the $\mathrm{Gly}_{2}$ peaks (Table 1 ) and by analysis of the sample using ion-pair high-performance liquid chromatography (IP-HPLC, see the Supporting Information). Consistent with the idea that the solid precipitate contained the paramagnetic metal that was previously in solution, a significant reduction in paramagnetic broadening was also 

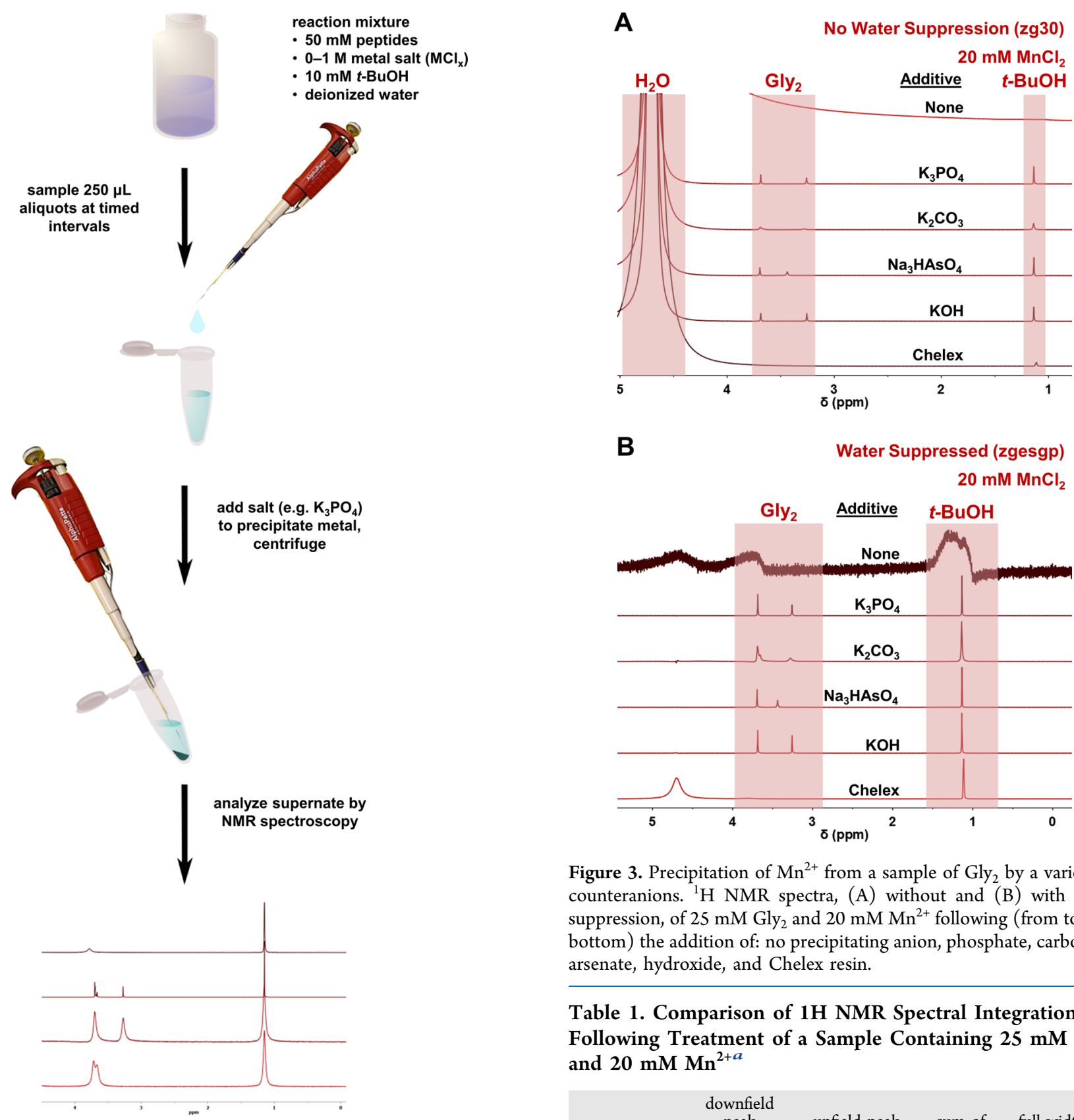

Figure 3. Precipitation of $\mathrm{Mn}^{2+}$ from a sample of $\mathrm{Gly}_{2}$ by a variety of counteranions. ${ }^{1} \mathrm{H}$ NMR spectra, (A) without and (B) with water suppression, of $25 \mathrm{mM} \mathrm{Gly}_{2}$ and $20 \mathrm{mM} \mathrm{Mn}^{2+}$ following (from top-tobottom) the addition of: no precipitating anion, phosphate, carbonate, arsenate, hydroxide, and Chelex resin.

Table 1. Comparison of $1 \mathrm{H}$ NMR Spectral Integration Following Treatment of a Sample Containing $25 \mathrm{mM} \mathrm{Gly} \mathrm{y}_{2}$ and $20 \mathrm{mM} \mathrm{Mn}^{2+a}$

$\begin{array}{ccccc} & \begin{array}{c}\text { downfield } \\ \text { peak } \\ \text { integration } \\ \text { (A) }\end{array} & \begin{array}{c}\text { upfield peak } \\ \text { integration } \\ \text { (B) }\end{array} & \begin{array}{c}\text { sum of } \\ \text { Gly } \\ \text { integration }\end{array} & \begin{array}{c}\text { full width half } \\ \text { maximum } \\ (\mathrm{Hz})\end{array} \\ \begin{array}{c}\text { no salt } \\ \text { (control) }\end{array} & \mathrm{N} / \mathrm{A} & \mathrm{N} / \mathrm{A} & \mathrm{N} / \mathrm{A} & 334.67 \\ \mathrm{~K}_{3} \mathrm{PO}_{4} \text { added } & 1.01 & 1.08 & 2.09 & 4.03 \\ \mathrm{~K}_{2} \mathrm{CO}_{3} \text { added } & 0.58 & 0.20 & 0.78 & 7.69 \\ \mathrm{Na}_{3} \mathrm{HAsO}_{4} & 0.58 & 0.63 & 1.21 & 5.52 \\ \text { added } & & & & \\ \text { KOH added } & 0.70 & 0.85 & 1.55 & 4.94 \\ \text { Chelex added } & \text { N/A } & \text { N/A } & \text { N/A } & 51.88\end{array}$

Figure 2. Schematic summary of the precipitation method. A schematic representation of the procedure used to prepare samples for analysis by NMR spectroscopy.

observed in a sample to which we added Chelex, a metalchelating solid resin, rather than a precipitating anion.

To construct a quantitative evaluation of the effectiveness of phosphate as a precipitating agent, we screened its use against a variety of paramagnetic metals. In these experiments, $250 \mu \mathrm{L}$ of $100 \mathrm{mM} \mathrm{K}_{3} \mathrm{PO}_{4}$ was added to $250 \mu \mathrm{L}$ aliquots of $25 \mathrm{mM}$ $\mathrm{Gly}_{2}$ with $20 \mathrm{mM} \mathrm{MnCl}, \mathrm{CuCl}_{2}, \mathrm{FeCl}_{2}, \mathrm{FeCl}_{3}, \mathrm{CoCl}_{2}$, or $\mathrm{NiCl}_{2}$. The resulting NMR spectra appear in Figure $\mathrm{S} 2$ in the Supporting Information. We used inductively coupled plasmaoptical emission spectroscopy (ICP-OES) to measure the concentration of the paramagnetic metals in solution both before and after precipitation. In general, the samples that had lower remaining concentrations of metals produced better spectra (e.g., $\mathrm{Mn}^{2+}$ and $\mathrm{Co}^{2+}$ ) than the samples that had larger

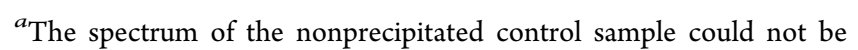
integrated because of catastrophic line broadening.

residual concentrations of metal (e.g., $\mathrm{Fe}^{3+}$ ). This observation is consistent with both $\mathrm{Mn}_{3}\left(\mathrm{PO}_{4}\right)_{2}$ and $\mathrm{Co}_{3}\left(\mathrm{PO}_{4}\right)_{2}$ having $K_{\mathrm{sp}}$ values over 10 orders of magnitude lower that the $K_{\mathrm{sp}}$ value of $\mathrm{FePO}_{4}$.

NMR spectra of the same samples with water suppression made it evident that the method is not without its faults. Some 
of the integration ratios between the peptide and $t-\mathrm{BuOH}$ were thrown off, suggesting that the solid phase might also contain some of the peptide substrate and/or the internal standard used to monitor the concentration of substrate present in solution. This problem was particularly evident for the Chelex resin. We assume that the hydrophobic resin-a copolymer of styrene and divinylbenzene-bearing iminodiacetic acid groups-can bind nonspecifically to organic substrates, removing an unpredictable amount of these compounds from the sample. ${ }^{31}$

Keeping in mind the particular sensitivity of thioester substrates to strongly basic conditions, we explored the use of salts of the same counteranions as mentioned previously but protonated (e.g., $\mathrm{KH}_{2} \mathrm{PO}_{4}$ and $\mathrm{K}_{2} \mathrm{HPO}_{4}$ rather than $\mathrm{K}_{3} \mathrm{PO}_{4}$ ) so that they would not render the samples as alkaline, following the precipitation reaction. In these cases, at lower values of $\mathrm{pH}$, the precipitation reactions were not sufficient to enable a deuterium lock on the spectrometer, and no sensible spectra could be obtained. These results are consistent with reports of higher $K_{\mathrm{sp}}$ values for metal salts of basic anions in increasingly acidic solutions. $^{32,33}$

We treated a mixture of $25 \mathrm{mM} \mathrm{Gly}_{2}+28 \mathrm{mM} \mathrm{MnCl}_{2}$ with increasing concentrations of $\mathrm{K}_{3} \mathrm{PO}_{4}$ to assess the effects on the metal removed. The results summarized in Table S7 and Figure S4 showed that increasing the concentration of the phosphate stock from 10 to $100 \mathrm{mM}$ resulted in a reduction of the concentration of $\mathrm{Mn}^{2+}$ remaining in the precipitated sample from $14 \mathrm{mM}$ (at $\mathrm{pH}$ 6, giving a poor-quality spectrum) to $0.4 \mathrm{mM}$ (at $\mathrm{pH} \mathrm{12,} \mathrm{giving} \mathrm{a} \mathrm{spectrum} \mathrm{that} \mathrm{could} \mathrm{be}$ integrated). Increasing the equivalents of precipitating ions to the metal removes an increasing amount of metal but comes with the cost of raising the $\mathrm{pH}$ of the precipitated solution.

Furthermore, we treated a mixture of $25 \mathrm{mM} \mathrm{Gly}_{2}+28 \mathrm{mM}$ $\mathrm{MnCl}_{2}$ with $100 \mathrm{mM}$ of $\mathrm{K}_{3} \mathrm{PO}_{4}, \mathrm{~K}_{2} \mathrm{HPO}_{4}$, or $\mathrm{KH}_{2} \mathrm{PO}_{4}$ to assess the effects of $\mathrm{pH}$ on the metal removed. The results are summarized in Table S6 and Figure S3. The pH of the final precipitated solutions were 12,8 , and 5 , respectively. The final concentrations of $\mathrm{Mn}^{2+}$ were $0.4,1.2$, and $22.3 \mathrm{mM}$, respectively. Thus, for equal concentrations of phosphates, increasingly alkaline conditions favored removal of more metal and significantly improved NMR spectra.

These results constitute a major limitation of the method: some $K_{\mathrm{sp}}$ values of the paramagnetic salts are not sufficiently low to remove enough of the paramagnetic cation from solution to enable analysis by NMR spectroscopy. The limitation becomes a greater challenge as the $\mathrm{pH}$ of the solution becomes increasingly acidic. We found it impossible to use the method to reliably analyze reactions of thioesters because (i) at $\mathrm{pH}<12$, the precipitation reaction did not remove enough of the paramagnetic metal from solution and (ii) at $\mathrm{pH}>12$, although we could obtain better spectra, the thioester hydrolyzed significantly during the analysis. Figures S10 and S11 in the Supporting Information show that acetic acid $(\delta=1.5-2.0 \mathrm{ppm})$ - the hydrolysis product of $S$-methyl thioacetate (SMTA)-forms immediately, following the addition of the alkaline precipitating salts. These observations are consistent with SMTA's half-life of $7.2 \mathrm{~min}$ at $\mathrm{pH} 12$. $^{3}$

For samples tolerant of base, the improvement of NMR spectra can be quite compelling. Figure 4 demonstrates the improvement of the ${ }^{1} \mathrm{H}$ NMR spectrum of $\mathrm{Ala}_{2}$ obtained when $20 \mathrm{mM}$ of $\mathrm{Mn}^{2+}$ is removed by precipitation with potassium phosphate. Here, the $\mathrm{Ala}_{2}$ is stable to the strongly basic conditions required of the precipitation reaction (we see no

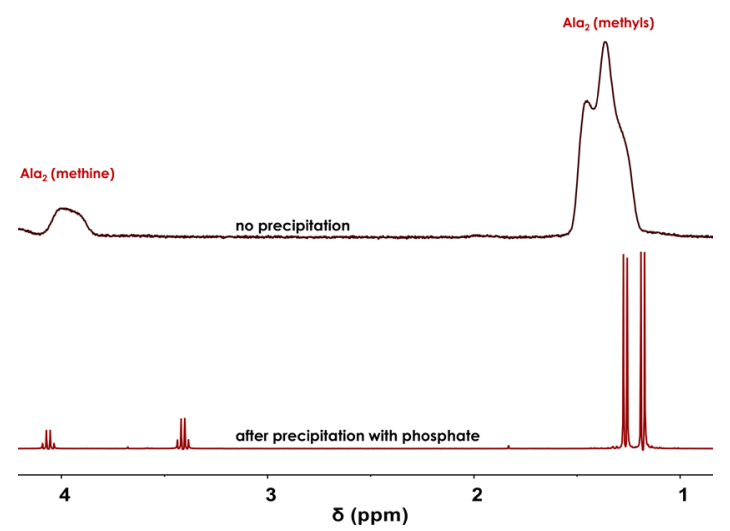

Figure 4. ${ }^{1} \mathrm{H}$ NMR spectra of $\mathrm{Ala}_{2}$ with $\mathrm{Mn}^{2+}$ improved by precipitation. Demonstration of how precipitation of a paramagnetic metal from a sample can improve the resolution of an NMR spectrum of an organic compound in water. Top: spectrum of $50 \mathrm{mM}$ L-alanylL-alanine $\left(\mathrm{Ala}_{2}\right)$ with $20 \mathrm{mM} \mathrm{Mn}{ }^{2+}$ in $1 \mathrm{M} \mathrm{HCl}$. Bottom: spectrum of the same sample following the addition of an equal volume of $1.5 \mathrm{M}$ $\mathrm{K}_{3} \mathrm{PO}_{4}$ to precipitate most of the metal present.

new peak for free alanine that would be the product of hydrolysis). Indeed, this method is especially suitable for qualitative characterization where there are no concerns if the precipitation method removes a fraction of the organic compound(s) present from the solution. Of course, we sought to develop a method that would enable the measurement of reaction kinetics with quantitative accuracy, and we found our method to be suitable for monitoring reactions with organic substrates tolerant of basic conditions on short time scales, such as peptides. ${ }^{5}$

Figure 5 summarizes how the method was used to measure rate constants for the hydrolysis of glycylglycine $\left(\mathrm{Gly}_{2}\right)$ in aqueous $1 \mathrm{M} \mathrm{HCl}$ with $1 \mathrm{M} \mathrm{FeCl}_{2}, 1 \mathrm{M} \mathrm{MnCl}$, and no transition metal. As the two methylene signals for $\mathrm{Gly}_{2}$ gradually recede at longer reaction times, a single peak for glycine (Gly) gradually appears. From the integration values of these peaks, we constructed a linear plot corresponding to pseudo-first-order kinetics, from which we obtained observed rate constants for hydrolysis. The observed pseudo-first-order rate constant, $k_{\mathrm{obs}}$, is equal to the slope of the best-fit line. Gly 2 hydrolyzes more quickly in both $\mathrm{FeCl}_{2}$ or $\mathrm{MnCl}_{2}$ solutions than in the control sample, where no additional metal is present. The measured rate constants were $0.016,0.019$, and $0.019 \mathrm{~h}^{-1}$ for the standard, $\mathrm{FeCl}_{2}$, and $\mathrm{MnCl}_{2}$ samples, respectively.

Guidance to the Reader. This method for removing paramagnetic metals to enable NMR spectroscopy functions best under strongly alkaline conditions where the $K_{\mathrm{sp}}$ values for the metal salts are favorably low. At lower values of $\mathrm{pH}$, enough metal persists in the supernate to broaden peaks in the NMR spectra. At high $\mathrm{pH}$, reactions such as hydrolysis might be more likely to occur. Thus, this precipitation method tends to work best for substrates that are not sensitive to high $\mathrm{pH}$. For applications with substrates that are sensitive to high $\mathrm{pH}$, the use of Chelex can improve spectra but may be accompanied by loss of quantitative precision, as the Chelex resin appears to remove organic substances in addition to the metals.

Although effective in removing $\mathrm{Fe}^{2+}, \mathrm{Co}^{2+}$, and $\mathrm{Mn}^{2+}$, we observed some limitations to our method when it is applied to samples with $\mathrm{Fe}^{3+}$ and $\mathrm{Ni}^{2+}$ (see Figure S2 in the Supporting 
A

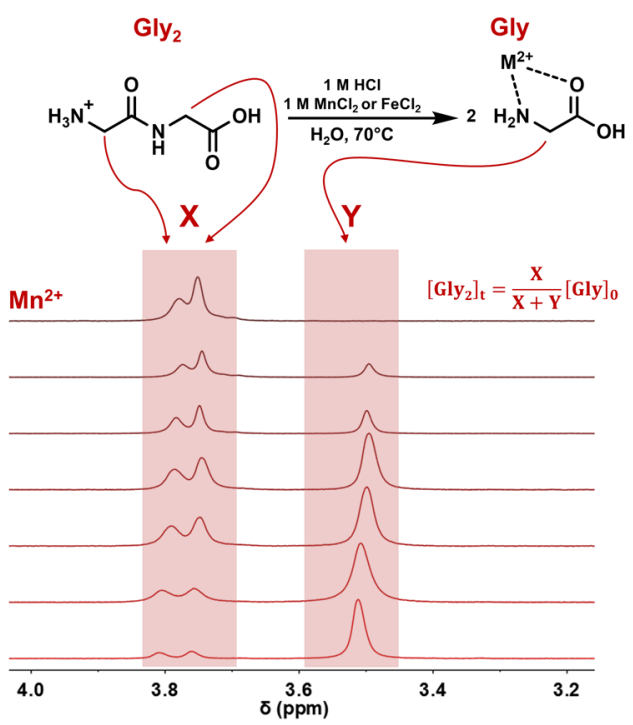

C

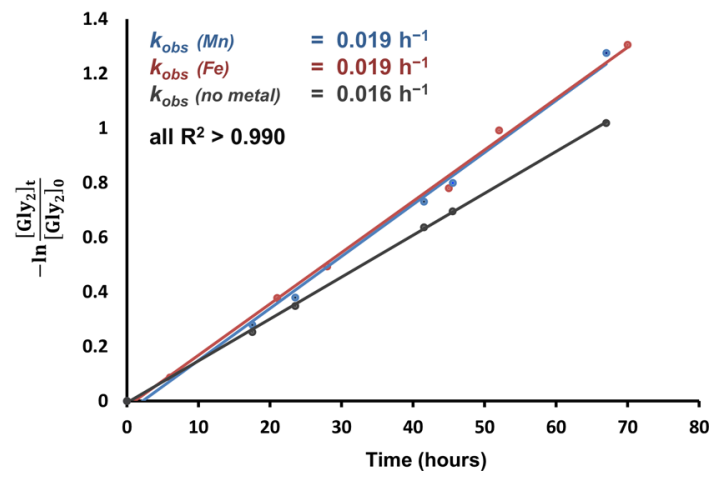

Figure 5. Kinetics of the hydrolysis of $\mathrm{Gly}_{2}$ in the presence of $\mathrm{Mn}^{2+}$ and $\mathrm{Fe}^{2+}$. (A) Hydrolysis of $50 \mathrm{mM} \mathrm{Gly}$ in $1 \mathrm{M} \mathrm{HCl}$ at $70{ }^{\circ} \mathrm{C}$ with no salt, $1 \mathrm{M} \mathrm{Fe}^{2+}$, and $1 \mathrm{M} \mathrm{Mn}^{2+}$. ${ }^{1} \mathrm{H}$ NMR peak assignments of the starting materials and products are indicated with red arrows. (B) ${ }^{1} \mathrm{H}$ NMR spectra for monitoring the $\mathrm{Mn}^{2+}$ reaction. Aliquots were sampled at timed intervals and treated with $\mathrm{K}_{3} \mathrm{PO}_{4}$ to precipitate the paramagnetic metal prior to collection of each spectrum. (C) Plots demonstrating the reactions are governed by pseudo-first-order kinetics when $\left[\mathrm{H}^{+}\right]$and $\left[\mathrm{M}^{n+}\right] \gg\left[\mathrm{Gly}_{2}\right]$.

Information). Last, we note that HPLC, including IPC, is an alternative method for monitoring the same peptide reactions studied here. ${ }^{11}$

In many systems, detection by UV-vis absorption or fluorescence emission would be possible in the presence of paramagnetic metals. UV-vis spectroscopy has been used to measure the rates of reactions of thioesters, which are better chromophores than glycyl peptides. ${ }^{6,34}$ Relative to these alternatives, the precipitation method described here could be preferable when (i) researchers lack access to a reliable HPLC instrument, (ii) the analytes lack chromophores, and (iii) the analyte is compatible with the alkaline conditions required for precipitation.

\section{CONCLUSIONS}

We report a method for collecting NMR spectra of organic compounds and monitoring their reactions by precipitating any transition metals present prior to analysis. This method for the removal of metals ensures that the presence of paramagnetic metals does not broaden peaks in the spectra. The principal advantages of our system are that it: (i) removes paramagnetic ions, (ii) permits complex mixtures that absorb all over the UV-vis spectrum, (iii) permits the NMR instrument to lock on the deuterated solvent, (iv) allows higher spectral resolution for ${ }^{1} \mathrm{H}$ NMR, and (v) does not add new organic species that could muddle the NMR spectra. Future efforts to identify precipitating anions that function at less alkaline values of $\mathrm{pH}$ could lead to a more versatile method.

\section{EXPERIMENTAL SECTION}

Standard Procedure for Sample Preparation. A reaction mixture was prepared for analysis by vortex mixing a vial with a $5 \mathrm{~mL}$ solution of known concentration $(5,10,20$ $\mathrm{mM}$, or $1 \mathrm{M}$ ) of a metal chloride [metal = manganese(II), copper(II), iron(II), iron(III), nickel(II), and cobalt(II)], 10 $\mathrm{mM}$ of internal standard $(t-\mathrm{BuOH})$, and $50 \mathrm{mM}$ of analyte (a thioester or a peptide) in deionized water. Each standard sample for NMR spectroscopy was prepared by vortex mixing a $125 \mu \mathrm{L}$ aliquot of the reaction mixture with $375 \mu \mathrm{L} \mathrm{D} \mathrm{D}_{2} \mathrm{O}$ in an NMR tube. Each precipitation sample was prepared by mixing $250 \mu \mathrm{L}$ of the supernatant of the precipitated mixture and 250 $\mu \mathrm{L} \mathrm{D}_{2} \mathrm{O}$. The precipitated mixture contains a $250 \mu \mathrm{L}$ aliquot of the reaction mixture with $250 \mu \mathrm{L}$ of the precipitating salt $\left(\mathrm{KOH}, \mathrm{K}_{2} \mathrm{CO}_{3}\right.$, or $\mathrm{K}_{3} \mathrm{PO}_{4}$ ) in excess concentration (e.g., 100 $\mathrm{mM}$ salt for $20 \mathrm{mM}$ metal samples, $1.5 \mathrm{M}$ salt for $1 \mathrm{M}$ metal samples) relative to the metal ion concentration (or, in the case of Chelex, $\sim 2 \mathrm{~g}$ of the resin) in a microcentrifuge tube. Table S3 in the Supporting Information contains a summary of precipitation experiments we conducted.

General Conditions for Kinetics Experiments. The reaction mixtures generally contained the peptide or thioester substrate, a soluble salt of a transition metal, hydrochloric acid, and water as the solvent. Aliquots of these mixtures were drawn at timed intervals and diluted with an equal volume of a sufficiently concentrated solution of the precipitating anion $\left(\mathrm{CO}_{3}{ }^{2-}, \mathrm{PO}_{4}{ }^{3-}\right.$, or $\left.\mathrm{AsO}_{4}{ }^{3-}\right)$ in $\mathrm{D}_{2} \mathrm{O}$. Thus, the reactions were run in pure $\mathrm{H}_{2} \mathrm{O}$, but the samples on which NMR spectra were collected had $\sim 1: 1 \mathrm{H}_{2} \mathrm{O} / \mathrm{D}_{2} \mathrm{O}$ as the solvent.

NMR Spectroscopy. Samples were analyzed on a Bruker (Billerica, Massachusetts) Avance III $400 \mathrm{MHz}$ NMR spectrometer with 16 scans and a recycle delay (d1) of $15 \mathrm{~s}$, which is greater than 7 times the $T_{1}$ relaxation time of the methylene protons of linear glycine peptides under the conditions of the analysis. ${ }^{1}$ All spectra were collected using a standard 1-D ${ }^{1} \mathrm{H}$ NMR and a 1-D excitation sculpting pulse programs (specifically, "zg30" and "zgesgp" on Bruker's TopSpin 3.2 software). All spectral data were processed with MestreNova software, version 11.0.3.

Kinetics of Hydrolysis of $\mathrm{Gly}_{2}$. In $20 \mathrm{~mL}$ scintillation vials, $10 \mathrm{~mL}$ of aqueous solutions were prepared with $0.1 \mathrm{M}$ $\mathrm{Gly}_{2}, 1.0 \mathrm{M} \mathrm{HCl}$, and one among $1 \mathrm{M} \mathrm{MnCl}_{2}, 1 \mathrm{M} \mathrm{FeCl}_{3}$, or no metal (as a control). The reaction mixtures were stirred at $70{ }^{\circ} \mathrm{C}$ for the duration of the experiment. At intervals of $8-12$ $\mathrm{h}$, a $250 \mu \mathrm{L}$ aliquot was removed from each reaction and immediately subjected to precipitation by the addition of 250 $\mu \mathrm{L}$ of $1.5 \mathrm{M} \mathrm{K}_{3} \mathrm{PO}_{4}$ in water. After the solid precipitate was spun down by centrifugation at $12000 \mathrm{rpm}(13500 \mathrm{~g})$ for 2 min, $250 \mu \mathrm{L}$ of the liquid supernate was mixed with $250 \mu \mathrm{L}$ of $\mathrm{D}_{2} \mathrm{O}$ in a standard $5 \mathrm{~mm}$ NMR tube for analysis by ${ }^{1} \mathrm{H}$ NMR spectroscopy at $400 \mathrm{MHz}$. Each reaction mixture was sampled at 5 time points, and the relative ratio of the reactant to the hydrolyzed product was determined and used to construct a plot of $-\ln \left(\left[\mathrm{Gly}_{2}\right]_{t} /\left[\mathrm{Gly}_{2}\right]_{0}\right)$ versus time. From this plot, the rate constant $(k)$ is derived by calculating the slope of the best- 
fit line and dividing by the concentration of acid and salt (here, $1 \mathrm{M}$ for both), according to the integrated pseudo-first-order rate law, as shown in eq S4 of the Supporting Information.

\section{ASSOCIATED CONTENT}

\section{S Supporting Information}

The Supporting Information is available free of charge athttps://pubs.acs.org/doi/10.1021/acsomega.9b02610.

Additional experimental detail of the HPLC method and practical notes for its application, materials, derivation of pseudo-first-order kinetics, NMR spectra of samples referred in this text, ICP-OES data, and additional references $(\mathrm{PDF})$

\section{AUTHOR INFORMATION}

\section{Corresponding Author}

*E-mail: paul.bracher@slu.edu.

ORCID $\odot$

Paul J. Bracher: 0000-0001-5769-8364

\section{Author Contributions}

P.J.B. conceived the project. C.H.C. conducted the initial experiments at the California Institute of Technology. R.F., J.P.R., and C.T.D. conducted experiments at Saint Louis University. All authors interpreted data. R.F. and P.J.B. primarily wrote the paper with input from all authors.

\section{Notes}

The authors declare no competing financial interest.

\section{ACKNOWLEDGMENTS}

This work was supported by the NASA EPSCoR Missouri Research Infrastructure Development Program funded through NASA Grant Cooperative Agreement Number NNX15AK38A. R.F. was also supported by the NSF and the NASA Astrobiology Program, under the NSF Center for Chemical Evolution (CHE-1504217). C.H.C. and J.P.R. were supported by Caltech Summer Undergraduate Research Fellowships. The NSF and Saint Louis University jointly funded the spectrometer used to acquire ICP-OES data through the NSF Major Research Instrumentation Program (award CHE1626501). We thank Prof. Harry B. Gray and Dr. Thomas D. Campbell for helpful discussions.

\section{REFERENCES}

(1) Campbell, T. D.; Hart, C. A.; Febrian, R.; Cheneler, M. L.; Bracher, P. J. The opposite effect of $\mathrm{K}^{+}$and $\mathrm{Na}^{+}$on the hydrolysis of linear and cyclic dipeptides. Tetrahedron Lett. 2018, 59, 2264-2267.

(2) De Duve, C. Blueprint for a Cell: the Nature and Origin of Life; N. Patterson: Burlington, N.C., 1991; p 275.

(3) Bracher, P. J.; Snyder, P. W.; Bohall, B. R.; Whitesides, G. M. The Relative Rates of Thiol-Thioester Exchange and Hydrolysis for Alkyl and Aryl Thioalkanoates in Water. Origins Life Evol. Biospheres 2011, 41, 399-412.

(4) Kaminskaia, N. V.; Kostić, N. M. New Selectivity in Peptide Hydrolysis by Metal Complexes. Platinum(II) Complexes Promote Cleavage of Peptides Next to the Tryptophan Residue. Inorg. Chem. 2001, 40, 2368-2377.

(5) Martin, R. B., Peptide Bond Characteristics. Metal Ions in Biological Systems; Taylor \& Francis: New York, NY, 2001.

(6) Patel, G.; Satchell, R. S.; Satchell, D. P. N. Slow metal transfer in hydrolyses promoted by gold(III) ions. Inorg. Chim. Acta 1981, 54, L97-L98.
(7) Sakata, K.; Yabuta, H.; Kondo, T. Effects of metal ions and $\mathrm{pH}$ on the formation and decomposition rates of di- and tri-peptides in aqueous solution. Geochem. J. 2014, 48, 219-230.

(8) Nakata, T.; Tasumi, M.; Miyazawa, T. Metal(II)-Ion Promoted Hydrolysis of Glycylglycine. Bull. Chem. Soc. Jpn. 1975, 48, 15991601.

(9) Patel, G.; Satchell, R. S. The kinetics and mechanism of the mercurous ion-promoted hydrolysis of S-thio esters. J. Chem. Soc., Perkin Trans. 2 1979, 458-461.

(10) Patel, G.; Satchell, R. S. The kinetics and mechanism of the thallium ion-promoted hydrolysis of thiol esters. J. Chem. Soc., Perkin Trans. 2 1980, 1403-1405.

(11) Long, D. A.; Truscott, T. G.; Cronin, J. R.; Lee, R. G. Peptide kinetics. Part 11.- Influence of divalent metal ions on rate of reaction of glycyl-glycine in the $\mathrm{pH}$ ranges $0.3-1.0$ and 3.8-6.0. Trans. Faraday Soc. 1971, 67, 1094-1103.

(12) Grant, K. B.; Kassai, M. Major Advances in the Hydrolysis of Peptides and Proteins by Metal Ions and Complexes. Curr. Org. Chem. 2006, 10, 1035-1049.

(13) Anbar, A. D. Elements and Evolution. Science 2008, 322, 14811483.

(14) Williams, R. J. P.; Frausto da Silva, J. J. R. The Chemistry of Evolution; Elsevier, 2006.

(15) Rohlfing, D. Thermal polyamino acids: synthesis at less than $100{ }^{\circ} \mathrm{C}$. Science 1976, 193, 68-70.

(16) Lahav, N.; White, D.; Chang, S. Peptide formation in the prebiotic era: thermal condensation of glycine in fluctuating clay environments. Science 1978, 201, 67-69.

(17) Forsythe, J. G.; Yu, S.-S.; Mamajanov, I.; Grover, M. A.; Krishnamurthy, R.; Fernández, F. M.; Hud, N. V. Ester-Mediated Amide Bond Formation Driven by Wet-Dry Cycles: A Possible Path to Polypeptides on the Prebiotic Earth. Angew. Chem. 2015, 127, 10009-10013.

(18) Mamajanov, I.; MacDonald, P. J.; Ying, J.; Duncanson, D. M.; Dowdy, G. R.; Walker, C. A.; Engelhart, A. E.; Fernández, F. M.; Grover, M. A.; Hud, N. V.; Schork, F. J. Ester Formation and Hydrolysis during Wet-Dry Cycles: Generation of Far-fromEquilibrium Polymers in a Model Prebiotic Reaction. Macromolecules 2014, 47, 1334-1343.

(19) Rodriguez-Garcia, M.; Surman, A. J.; Cooper, G. J.; SuarezMarina, I.; Hosni, Z.; Lee, M. P.; Cronin, L. Formation of oligopeptides in high yield under simple programmable conditions. Nat. Commun. 2015, 6, 8385.

(20) Campbell, T. D.; Febrian, R.; McCarthy, J. T.; Kleinschmidt, H. E.; Forsythe, J. G.; Bracher, P. J. Prebiotic condensation through wetdry cycling regulated by deliquescence. Nat. Commun. 2019, 10, 4508.

(21) Bertini, I.; Luchinat, C.; Parigi, G. Magnetic susceptibility in paramagnetic NMR. Prog. Nucl. Magn. Reson. Spectrosc. 2002, 40, 249-273.

(22) Keller, M. A.; Zylstra, A.; Castro, C.; Turchyn, A. V.; Griffin, J. L.; Ralser, M. Conditional iron and $\mathrm{pH}$-dependent activity of a nonenzymatic glycolysis and pentose phosphate pathway. Sci. Adv. 2016, 2, No. e1501235

(23) Giraudeau, P.; Silvestre, V.; Akoka, S. Optimizing water suppression for quantitative NMR-based metabolomics: a tutorial review. Metabolomics 2015, 11, 1041-1055.

(24) Magritek. An Introduction to the Synthesis and Reactions of Ferrocene, http://www.azom.com/article.aspx?ArticleID=11350 (accessed 2014).

(25) Hill, J. Sulfur and the Origins of Life; Web, University of Canterbury: Canterbury, 2000.

(26) Donahue, C. J.; Donahue, E. R. Beyond Acetylferrocene: The Synthesis and NMR Spectra of a Series of Alkanoylferrocene Derivatives. J. Chem. Educ. 2013, 90, 1688-1691.

(27) Ding, S.; Xu, D.; Li, B.; Fan, C.; Zhang, C. Improvement of ${ }^{31} \mathrm{P}$ NMR spectral resolution by 8-hydroxyquinoline precipitation of paramagnetic $\mathrm{Fe}$ and $\mathrm{Mn}$ in environmental samples. Environ. Sci. Technol. 2010, 44, 2555-2561. 
(28) Barge, L. M.; Flores, E.; Baum, M. M.; VanderVelde, D. G.; Russell, M. J. Redox and $\mathrm{pH}$ gradients drive amino acid synthesis in iron oxyhydroxide mineral systems. Proc. Natl. Acad. Sci. U.S.A. 2019, 116, 4828-4833.

(29) Abesadze, T. S.; Buishvili, L. L.; Kobakhidze, G. V. Suppression of magnetic broadening of the optical impurity absorption line by polarized pulses. J. Phys.: Condens. Matter 1992, 4, 5611-5616.

(30) Jain, S. K.; Siaw, T. A.; Equbal, A.; Wilson, C. B.; Kaminker, I.; Han, S. Reversal of Paramagnetic Effects by Electron Spin Saturation. J. Phys. Chem. C 2018, 122, 5578-5589.

(31) Chelex 100 and Chelex 20 Chelating Ion Exchange Resin Instruction Manual; Laboratories, B.-R., Ed.; Bio-Rad Laboratories: California, 2000, Vol. LIT200 Rev B.

(32) Feitknecht, W.; Schindler, P., Solubility Constants of Metal Oxides, Metal Hydroxides and Metal Hydroxide Salts in Aqueous Solution. In IUPAC: Pure and Applied Chemistry; Burrows, H.; Stohner, J., Eds., 1963; p 74.

(33) Scholz, F.; Kahlert, H. The calculation of the solubility of metal hydroxides, oxide-hydroxides, and oxides, and their visualisation in logarithmic diagrams. ChemTexts 2015, 1, 7.

(34) Satchell, D. P. N.; Secemski, I. I. The kinetics and mechanism of metal ion promoted thiol ester hydrolysis. Tetrahedron Lett. 1969, 10, 1991-1994. 